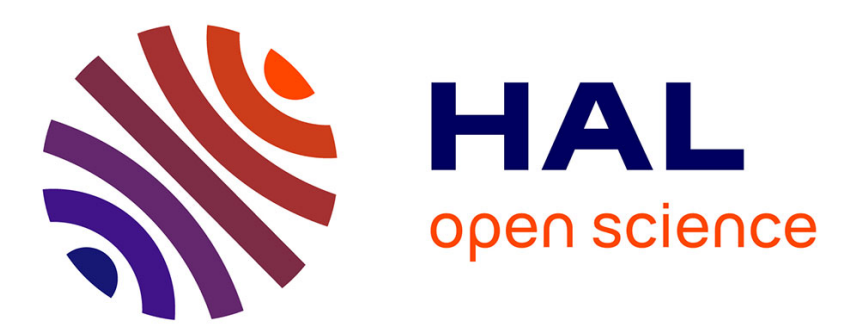

\title{
Development and mechanical characterization of porous titanium bone substitutes
}

\author{
Alexandre Barbas, Anne-Sophie Bonnet, Paul Lipinski, Raphaël Pesci, \\ Guillaume Dubois
}

\section{- To cite this version:}

Alexandre Barbas, Anne-Sophie Bonnet, Paul Lipinski, Raphaël Pesci, Guillaume Dubois. Development and mechanical characterization of porous titanium bone substitutes. Journal of the mechanical behavior of biomedical materials, 2012, 9, pp.34-44. 10.1016/j.jmbbm.2012.01.008 . hal-00959501

\section{HAL Id: hal-00959501 https://hal.science/hal-00959501}

Submitted on 14 Mar 2014

HAL is a multi-disciplinary open access archive for the deposit and dissemination of scientific research documents, whether they are published or not. The documents may come from teaching and research institutions in France or abroad, or from public or private research centers.
L'archive ouverte pluridisciplinaire HAL, est destinée au dépôt et à la diffusion de documents scientifiques de niveau recherche, publiés ou non, émanant des établissements d'enseignement et de recherche français ou étrangers, des laboratoires publics ou privés. 


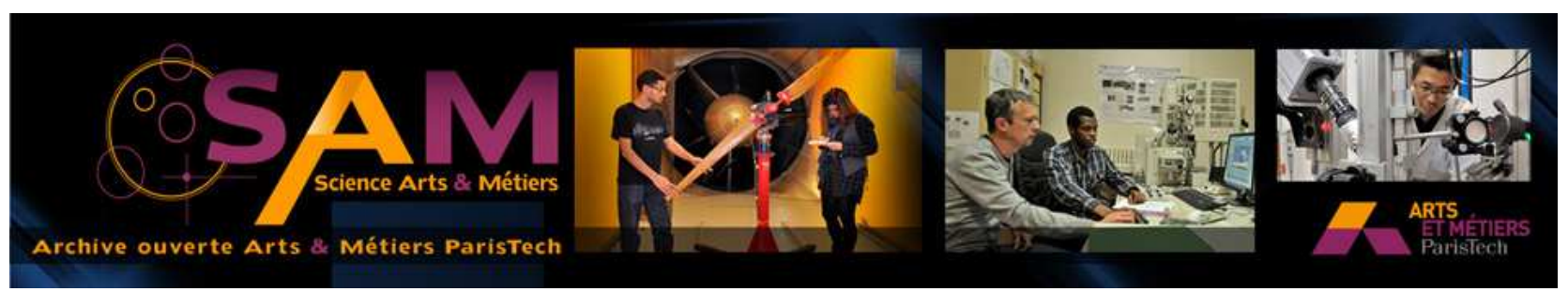

\section{Science Arts \& Métiers (SAM)}

is an open access repository that collects the work of Arts et Métiers ParisTech researchers and makes it freely available over the web where possible.

This is an author-deposited version published in: http://sam.ensam.eu

Handle ID: .http://hdl.handle.net/10985/7856

\section{To cite this version :}

Alexandre BARBAS, Anne-Sophie BONNET, Paul LIPINSKI, Raphaël PESCI, Guillaume DUBOIS - Development and mechanical characterization of porous titanium bone substitutes - Journal of the Mechanical Behavior of Biomedical Materials - Vol. 9, p.34-44 - 2012 


\title{
Development and mechanical characterization of porous titanium bone substitutes
}

\author{
A. Barba s a,b, A.-S. Bonnet a, P. Lipinski a, *, R. Pesci c, G. Dubois b \\ aLaBPS/ENIM, 1route d'Ars Laquenexy -CS 65820, 57078 Metz Cedex, France \\ b OBL Paris, Immeuble Vecteur Sud, 70-86 avenue de la République, 92320 Châtillon, France \\ c ENSAM-Arts et Métiers ParisTech, LEM3 UMR CNRS 7239, 4 rue Augustin Fresnel, 57070 Metz, France
}

Keywords:

Porous titanium

Implants

Bone substitute

Mechanical properties

Anisotropy

\begin{abstract}
A B S T R A C T
Commercially Pure Porous Titanium (CPPTi) can be used for surgical implants to avoid the stress shielding effect due to the mismatch between the mechanical properties of titanium and bone. Most researchers in this area deal with randomly distributed pores or simple architectures in titanium alloys. The control of porosity, pore size and distribution is necessary to obtain implants with mechanical properties close to those of bone and to ensure their osseointegration. The aim of the present work was therefore to develop and characterize such a specific porous structure. First of all, the properties of titanium made by Selective Laser Melting (SLM) were characterized through experimental testing on bulk specimens. An elementary pattern of the porous structure was then designed to mimic the orthotropic properties of the human bone following several mechanical and geometrical criteria. Finite Element Analysis (FEA) was used to optimize the pattern. A porosity of 53\% and pore sizes in the range of 860 to $1500 \mu \mathrm{m}$ were fi.nally adopted. Tensile tests on porous samples were then carried out to validate the properties obtained numerically and identify the failure modes of the sam_ples. Final!y, FE elasto_plastic ana!yses wereyerformed on the porous samples in order to propose a failure criterion for the design of porous substitutes.
\end{abstract}

\section{Introduction}

In most cases, clinical failure of prosthetic solutions is due to the stress-shie lding generated by the mismatch of mechanical properties between bone and implant (Karachalios et al., 2004). The mechanica 1 properties of bone depend on many factors such as anatomical part, sex and age. The global elastic properties of cortical bone are usually described by the orthotropic tensor of elastic moduli defined by nine constants. Its longitudinal compressive strength was estimated to be
200 MPa by Reilly and Burstein (1975) and Reilly et al. (1974). In long bones, the cortical tissue represents approximately $25 \%$ of the whole bone volume. Consequently, as a first order approximation an apparent compressive strength of $50 \mathrm{MPa}$ is considered in this study.

The intrinsic properties of bulk titanium are significant ly higher than those of cortical bone. To minimize the negative impact of this stiffness incompatibility, substitutes with a controlled porosity can be introduced. Oh et al. (2003) obtained the Young's modulus of porous titanium close to that of bone by changing the voids volume fraction $f v$. They 
reduced this property from $110 \mathrm{GPa}$ (bulk titanium) to $10 \mathrm{GPa}$ for $f \mathrm{~V}=0.35$.

Moreover, as demonstrated by many authors (Otsuki et al., 2006 ; Heinl et al., 2008; Xue et al., 2007 ; Hollander et al., 2006), the existence of porosity is also propitious for the substitute osseointegration, the essential factor of the longterm reliability of the implant. The question arises : do the size, shape, topology and volume fraction of voids have any influence on the substitute colonization? Only a few studies have addressed this crucial problem. There is no consensus in the literature about the optimal pore size to enhance bone ingrowth . In their pioneering work, Otsuki et al. (2006) showed that the pores of the structure have to be interconnected in order to ensure the bone ingrowth. These authors also compared the type of tissue formed as a function of time and implant internal architecture. They tested two levels of porosity $(50 \%$ and $70 \%)$ combined with two ranges of pore sizes (between 250 and $500 \mu \mathrm{m}$ and between 500 and $1500 \mu \mathrm{m}$ ) and concluded that the size of pores should range from 500 to $1500 \mu \mathrm{m}$ for both levels of porosity to get a tissue of good quality. Xue et al. (2007) demonstrated that the bone colonization is impossible for a pore size under $100 \mu \mathrm{m}$. Chen et al. (2009) tested the osteogenesis on structures with pores ranging from 100 to $400 \mu \mathrm{m}$ but did not speak out against higher pore dimensions. Hollander et al. (2006) tested porous structure with pore dimensions of 500,700 and $1000 \mu \mathrm{m}$ and concluded that the growth of human osteoblast is possible for all these types of porosities. Those authors did not indicate a maximal pore size either. Generally speaking, no clearly identified rule exists to allow the optimal design of implants or bone substitutes in commercially pure porous titanium (CPPTi).

Several manufacturing processes of porous titanium are known among which freeze casting (Yook et al., 2009), space holder technique (Niu et al., 2009), rapid prototyping ( $\mathrm{Li}$ et al., 2006) or laser processing (Parthasarathy et al., 2010; Heinl et al., 2008; Krishna et al., 2007). Freeze casting and space holder processes mostly lead to randomly distributed pores whereas rapid prototyping and laser processing are adopted when a controlled architecture is required.

The freeze casting technique enables a porous material with a compressive strength close to that of bone to be obtained, but its main drawback underlined by Yook et al. (2009) is the pore size that does not exceed $300 \mu \mathrm{m}$ for a long manufacturing time of 7 days. Higher pore sizes can be reached with the space holder technique but the mechanical properties obtained are lower than those of human bone (Niu et al., 2009). In both cases, the control of the elastic properties anisotropy seems to be difficult.

In the literature, rapid prototyping and laser processing are often reported to generate bulk titanium or porous titanium with simple pore architecture (Parthasarathy et al., 2010 ; Heinl et al., 2008; Krishna et al., 2007 ; Li et al., 2006). These techniques are generally used in the case of titanium alloys.

In this paper, the Selective Laser Melting (SLM) process was chosen to produce porous titanium with a particular periodic internal architecture. In a first part, the properties of titanium samples processed by SLM are studied and compared to the ISO Standard Specifications. Crystallographic texture and residual stress measurements are also examined to estimate the anisotropy of samples obtained by this technology.

In a second part, an elementary pattern is designed to approach the mechanical properties of human bone and to enable the optimal implant osteointegration. The final section is dedicated to the question of elastoplastic global properties and simple failure assessment for such porous implants.

\section{Materials and methods}

\subsection{Criteria for elementary pattern definition}

To design and optimize an elementary pattern for bone substitutes, several criteria had to be simultaneously taken into account. With biocompatibility, the criteria adopted in this study are as follows:

- Elastic (global) properties as close as possible to those of cortical bone (including the anisotropy).

- A maximal allowed apparent stress not exceeding $50 \mathrm{MPa}$.

- A maximal stress exerted at any point of the pattern smaller than $a a d=a y / k$, where ay is the yield point of the $\mathrm{CP} \mathrm{Ti}$ and $k=1.5$ corresponds to a safety coefficient.

- Interconnected pores (Otsuki et al., 2006).

- A pore size greater than $100 \mu \mathrm{m}$ to facilitate bone colonization (Shiomi et al., 2004; Xue et al., 2007; Chen et al., 2009).

- A porosity in the range of $50 \%$ to $70 \%$ as defined by Otsuki et al. (2006).

- A pattern shape enabling the perfect periodic paving of 30 space.

To perform such an optimization, the mechanical properties of commercially pure titanium processed by SLM have to be identified first. A classical experimental procedure is adopted to characterize the elastoplastic properties of CP Ti.

\subsection{Characterization of CP Ti processed by SLM}

Elastoplastic properties of CP Ti processed by SLM

To characterize the intrinsic properties of $\mathrm{CP}$ Titanium processed by SLM, three types of standard tensile test specimens (NF EN ISO 6892-1) have been manufactured with a SLM machine prototype. The direction of powder layer deposit varied for each type of specimen and was either longitudinal (L), transverse (W) or through specimen thickness (T). According to the standard, the dimensions of the gauge part of the samples have been fixed to $7 \mathrm{~mm}(\mathrm{~L}) \mathrm{x}$ $3 \mathrm{~mm}(\mathrm{~W}) \times 0.5 \mathrm{~mm}(\mathrm{~T})$. The actual raw gauge sections of the specimens were measured after fabrication with an optical 30 measurement device (InfiniteFocus, Alicona, Austria) .

The elastoplastic properties of the material have been determined using an Instron 5866 tension/compression testing machine equipped with a load-cell allowing a precise force measurement with an error less than $0.4 \%$ in the range of $0.1-10 \mathrm{kN}$. The Bluehill 2 software package was used to control the nominal stress rate during tests . A video tension device developed by Apollor ${ }^{\circledR}$ enabled the strain measurement. All the tests have been carried out at room temperature and quasi-static strain rate $\left(10-^{3} \mathrm{~s}-1\right)$. 


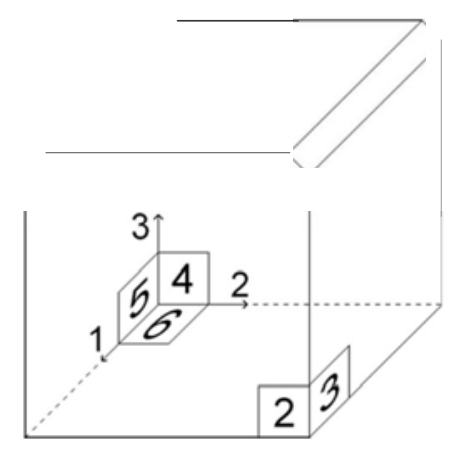

Fig. 1 - Scheme of a cubic specimen used for the residual stress measurements.

Crystallographic texture and resid ual stress measurement

Because of the high temperature gradient induced by SLM during material melting, residual stresses and pronounced crystallographic texture are often observed inside the parts produced with this fabrication process. These quantities generally lead to the appearance of an induced anisotropy of the material and influence its fatigue life.

In the present work, a four circles Seifert XRD 3003 PTS goniometer was used to determine the crystallographic texture of a $10 \times 10 \times 10 \mathrm{~mm}^{3}$ cubic specimen fabricated by SLM. Since the alpha titanium is obtained by SLM, the $\{101\}$ crystallographic planes were analysed on two faces of this sample and the corresponding pole figures were obtained.

The residual stresses were determined with a Proto IXRD goniometer equipped with a copper tube. In accordance with the European standard, the $\sin ^{2} \boldsymbol{t}$ method was used considering the $\{213\}$ planes. Tura $5 \times 5 \times 5 \mathrm{~mm}^{3}$ cubic specimens were prepared for these tests. The geometry and face designation as well as the coordinate frame attached to the cubes are indicated in Fig. 1.

The measurement of residual stresses was performed on the six faces of bath cubes in order to study the influence of the powder deposit and melting directions. For each specimen, the deposit direction corresponded to axis 3 and started from face 6 (bottom). After powder deposition, the external wall of the layer was melted followed by the filling of its core in the direction 1 or 2 . To avoid the generation of a preferred orientation, for each next deposited layer the melting direction was permuted.

\subsection{Design and fmite element improvement of the elementary pattern geometry}

The elementary patterns were first designed in the software package Solidworks 2003 respecting the various criteria cited in Section 2 .1concerning the minimal pore size, porosity and perfect paving of 30 space. Elastic Finite Element analyses were performed to improve the design. The FE meshes for all patterns were created using MSC Marc Software. Because of the existence of three planes of symmetry, only one eighth of every elementary pattern was meshed using hexahedral and pentahedral elements. Periodicity conditions were applied to the model on the appropriate faces. An example of the FE mesh can be appreciated in Fig. 2. The same software was used to perform the finite element analyses. Tura types of

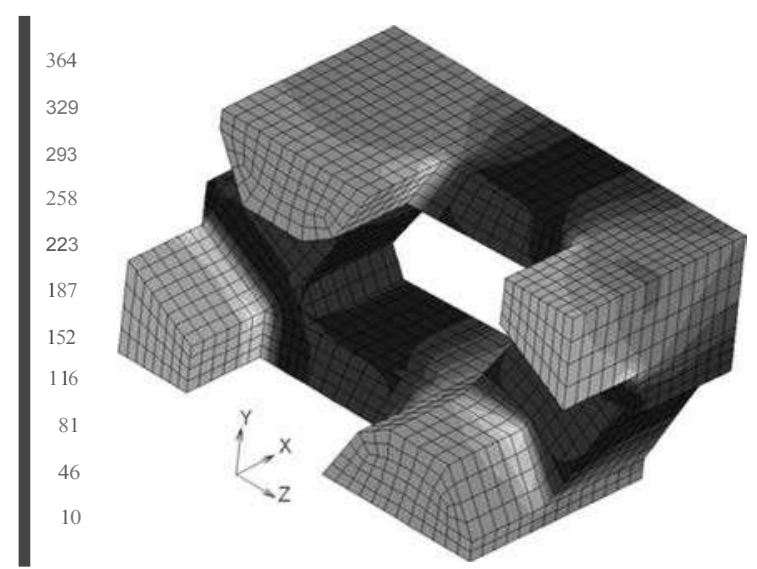

Fig. 2 - Equivalent von Mises stress on the elementary pattern submitted to an apparent equivalent stress of $50 \mathrm{MPa}$ in X direction.

load leading to an apparent equivalent stress of $50 \mathrm{MPa}$ were applied to identify the global elastic orthotropic properties of the pattern. Simple tension in the three principal directions was modelled to determine Young's moduli Ex. Ey, Ez and Poisson's ratios $v X Y, v y z, v z x$. Pure shear in planes XOY, YOZ and ZOX was simulated to estimate transverse moduli GXY . Gyz and Gzx (see Fig. 2 for coordinate system definition). Based on the results of Section 2.2, the elastic behaviour of the bulk $\mathrm{CP}$ grade $2 \mathrm{Ti}$ was supposed to be isotropie. The average value of Young's modulus of $100 \mathrm{GPa}$ was deduced from these tests. The commonly admitted value of the Poisson's ratio of 0.33 was also used, see Shiomi et al. (2004). For each geometric configuration, the concentration factor of von Mises stress on individual beams constituting the pattern was analysed and compared to the material allowable stress. After each design of the elementary pattern, numerical simulations were done in order to check the resulting elastic properties. The design improvement was performed in loop until the properties of the pattern fitted the mechanical criteria outlined previously in this paper.

\subsection{De.finition of porous tensile specimens for the determination of substitute elastoplastic properties}

In order to verify the adequacy of the mechanical properties provided by the simulations on the optimized pattern with the ones of a porous structure generated by SLM, experimental tensile tests were carried out. The porous specimens used in this mechanical study are illustrated in Fig. 3 and were named $\mathrm{X}, \mathrm{Y}$ and $\mathrm{Z}$, in accordance with the coordinate system in Fig. 2 , depending on the orientation of the elementary pattern in the porous area with respect to tension direction. All specimens were manufactured using a SLM machine prototype. They were composed of a porous gauge area and two gripped ends in bulk titanium and were designed in such a manner that four elementary patterns were present in the tension direction and at least two patterns in the transverse directions, Fig. 3. For each direction tested, three samples were manufactured. The theoretical porous cross sections normal to the tension directions were $5.74 \times 9.95 \mathrm{~mm}^{2}, 4.2 \times 9.95 \mathrm{~mm}^{2}$ and $4.2 \times 11.5 \mathrm{~mm}^{2}$, 


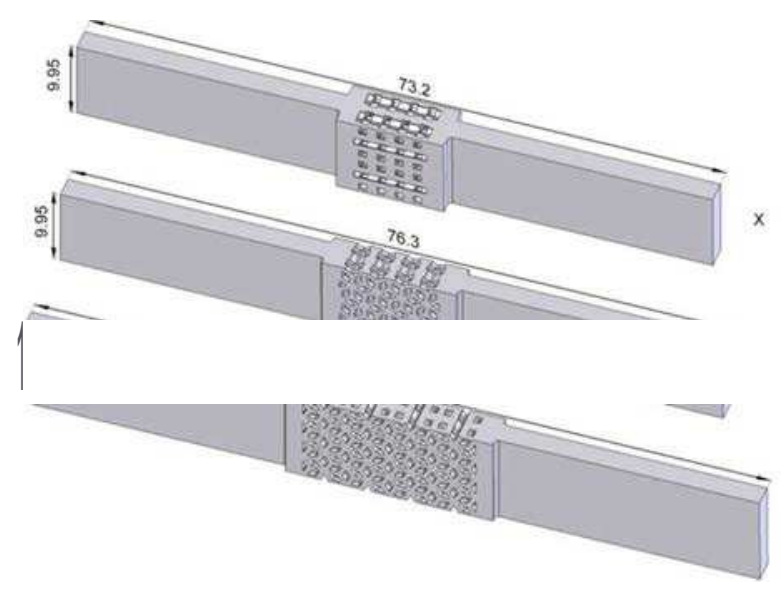

Fig. 3 - Tensile specimens of CPPTi (downwards: X, Y and $\mathrm{Z}$ type specimens).

respectively for the $\mathrm{X}, \mathrm{Y}$ and $\mathrm{Z}$ samples. The corresponding porous zone lengths were $8.4,11.49$ and $19.9 \mathrm{~mm}$ in the same order. The same experimental devices as those used for the mechanical tests on the bulk specimens were employed for these tensile experiments .

Concerning the effective elastic properties of these porous structures, only the Young's moduli were determined experimentally. The values of the remaining elastic constants (shear moduli and Poisson's ratios) were not characterized. The usual plastic properties of the porous titanium were identified, i.e. $\mathrm{Rp}_{0-2}, \mathrm{Rm}$ and $\mathrm{A} \%$. The true global and local (pore) dimensions of all nine specimens were characterized using a Phoenix Micro CT scan and compared with the theoretical ones.

To perform the measurement of the strain with the video-traction device, two points were marked on each specimen bulk part as illustrated in Fig. A .1 (Appendix). To characterize the mechanical properties of the porous titanium, the experimental force-displacement curves had to be corrected subtracting the stiffness of the bulk parts of the specimen. The details of this procedure are provided in Appendix.

The aim of these tests was to investigate the apparent elastoplastic properties of the porous structure and to observe the failure modes as a fonction of the pattern orientation with respect to the tensile direction

\subsection{Identification of porous implant dimensioning crite-} rion

An analysis of fractured tensile porous specimens was carried out in order to propose simple criteria enabling the dimensioning of SLM made porous implants .

The method used to identify the failure criterion of bone substitutes consisted in comparing experimental and numerical global stress-strain curves of porous tensile specimens .

The finite element meshes of the three types of specimen were built respecting the true specimen dimensions measured via Micro CT scanning. Only one eighth of each sample was meshed with mainly hexahedral elements using
Table 1 - Comparison between the SLM CP grade 2 Ti elastoplastic properties and the ISO 5832-2 (ISO 5832-2, 1999) specifications (SD enclosed in parentheses).

\begin{tabular}{llllr}
\multirow{2}{*}{ Property } & \multicolumn{3}{c}{ SLM CP grade 2 Ti } & \multirow{2}{*}{ ISO } \\
\cline { 2 - 3 } & \multicolumn{1}{c}{$\mathrm{L}$} & \multicolumn{1}{c}{$T$} & \\
\cline { 2 - 3 } $\mathrm{E}(\mathrm{GPa})$ & $91(12)$ & $100(5.5)$ & $101(2.6)$ & \\
$\mathrm{Rp}_{0.2}(\mathrm{MPa})$ & $522(18)$ & $518(5.5)$ & $533(2.1)$ & 230 \\
$\mathrm{Rm}(\mathrm{MPa})$ & $654(1.5)$ & $640(12.4)$ & $617(16.7)$ & 345 \\
$\mathrm{~A} \%$ & $17.0(3.0)$ & $14.7(2.9)$ & $5.1(2.1)$ & 20 \\
, thax & $12.2(1.7)$ & $11.3(1.3)$ & $3.6(1.4)$ & \\
\hline
\end{tabular}

Hypermesh software. The number of elements and degrees of freedom varied respectively from 107,204 to 204,608 and from 366,000 to 700,000 , in fonction of the specimen type. The $\boldsymbol{h}$ plastic flow theory was brought into play since only a monotonie loading was considered. The hardening curve of $\mathrm{CP} \mathrm{Ti}$ made by SLM determined in this work was introduced, see Section 2.2. The loading was reproduced by applying a ramp displacement - rime fonction on the nodes corresponding to the grip end of the sample. These boundary conditions enabled easy simulation of unstable specimen behaviour.

\section{Results and discussion}

\subsection{Elastoplastic properties of CP Ti grade 2 processed by} SLM

Three standard tensile test specimens of CP grade $2 \mathrm{Ti}$ were tested for each direction of melting. The true stress-true strain curves were obtained using the actual specimen cross sections. As an example, Fig. 4 shows the three curves obtained for the tension direction $(\mathrm{T})$. It clearly appears that SLM process ensures a good repeatability as the maximum stress deviation with respect to the average curve does not exceed $2 \%$. A similar conclusion can be drawn for the two other directions, not illustrated in this paper. Table 1 summarizes, for each melting direction, the average values of the usual elastoplastic material properties, i.e. Young's modulus $\mathrm{E}$, conventional yield stress $\mathrm{Rp}_{02}$, strength $\mathrm{Rm}$ and elongation A\% . Besides, the plastic strain Jmax corresponding to the maximum of stress-strain curve was also identified . The last column recalls the same characteristic, if available, provided by the ISO specification. This Table does not reveal any significant influence of the melting direction on the Young's modulus of SLM CP grade $2 \mathrm{Ti}$. The differences observed are mainly due to the precision of the experimental device which is not really adapted for measurement of elastic stiffness of bulk metallic materials. The conventional yield point and ultimate tensile strength are not influenced by this parameter either. However, the average elongation of the samples melted in (W) direction is significantly reduced compared to the two other directions. This is due to the mediocre quality of the sample surface after the removal of the sustaining structure. It is important to recall that all specimens were tested without any surface machining or mechanical treatment. The elongation value in (W) direction was discarded in the failure analysis presented in Section 3.5. 


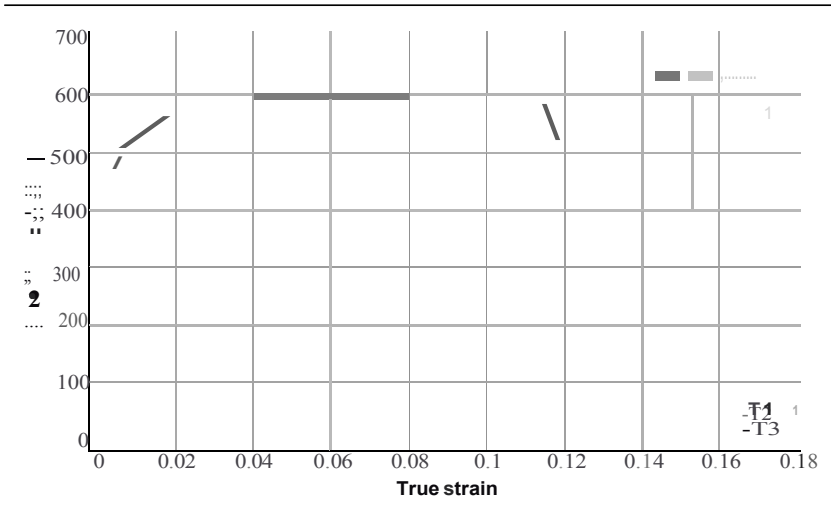

Fig. 4 - True stress-true strain curves of the (T) bulk specimens.

Compared with the ISO Standard Specification for unalloyed titanium 5832-2, the plastic properties of the SLM $\mathrm{CP}$ grade $2 \mathrm{Ti}$ are higher except for the material elongation . Indeed, the conventional yield point and ultimate tensile strength are almost twice as high as the ISO specifications.

On the one hand the elongation is reduced by $15 \%$ in L, 27\% in $\mathrm{T}$ and $75 \%$ in $\mathrm{W}$ directions. This important drawback can be partially attributed to the thickness of specimens tested ( $\mathrm{T}=0.5 \mathrm{~mm}-$ comparable with the diameter of porous pattern struts) which is relatively small with respect to the specimens roughness. Indeed a ten-point mean roughness of these specimens, obtained using Alicona InfiniteFocus microscope, was $\mathrm{R}_{2}=45 \mu \mathrm{m}$. On the other hand however, the SLM process is commonly used to manufacture patientspecific implants to suit the patient morphology. As a consequence, no adjustment by plastic deformation of implant is needed during surgery contrary to conventional implants. In such a situation, the critical elongation of the material is not necessarily a dimensioning parameter.

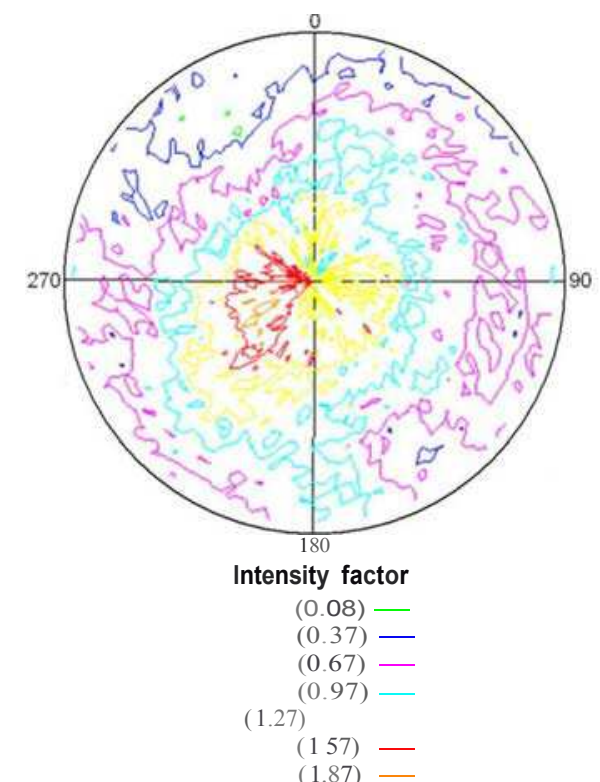

The trends reported in our study are in agreement with the results of Vandenbroucke and Kruth (2007) on SLM grade 5 titanium. These authors observed that the SLM process increases the yield point and ultimate tensile strength by $50 \%$ and reduces the elongation by $25 \%$.

\subsection{Crystallographic texture and residual stress measure- ment}

The two pole figures obtained from the crystallographic analysis are illustrated in Fig. 5, showing maps of the iso-lines of the orientation intensity factor. It is commonly recognized that the tested material becomes textured when this intensity factor is higher than 3. As the two pole figures indicate intensity factors not exceeding 2.3 , it can be concluded that there is no preferred crystallographic orientation of grains constituting the sample. Consequently, the randomly distributed texture of this SLM-processed titanium leads to the isotropy of its elastic and plastic properties, at least initially.

The results of the residual stress analysis are reported in Table 2. The residual stresses have only been measured on the external faces of the cubes. This Table shows that five faces of the examined cubes are subjected to a bi-axial compressive stress state. Face 1, however, undergoes positive stresses. This result can, at least partially, be attributed to the cooling process of the samples studied. First of all, it must be noted that faces 6 and 1correspond respectively to the first and last deposited layers. During the SLM process, layer $n$ is directly affected by the cooling of layer $n+1$ consecutive to its melting. Indeed, the thermal contraction during the cooling of layer $n+1$ generates compression in layer $n$ and tension in layer $n+1$. Therefore face 1 is subjected to tension and face 6 to compression. These faces having the normal vector parallel to axis 3 of coordinate system attached, only $a_{11}$ and a22 stress components are different from zero. A similar

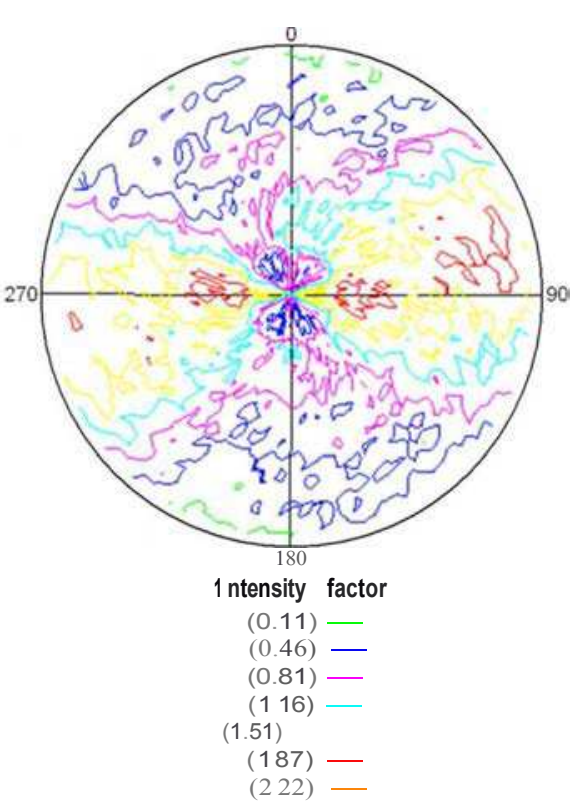

Fig. 5 - $\{101\}$ pole figures of alpha titanium on two faces of a cubic sample made by SLM. 


\section{Table 2 - Residual stresses measured on the external \\ faces of cubic specimens (MPa). Ali the values for \\ samples 1 and 2 are given $\pm 10 \mathrm{MPa}$.}

Stress
component
$(\mathrm{MPa})$

\begin{tabular}{lllll}
\hline \multirow{2}{*}{ Face 1 } & au & 180 & 140 & $160 \pm 30$ \\
& an & $7 \mathrm{~S}$ & -70 & $2 . \mathrm{S} \pm 100$ \\
Face 2 & $a 33$ & -30 & -80 & $-\mathrm{SS} \pm 3 \mathrm{~S}$ \\
& $a 22$ & -20 & -40 & $-30 \pm 1 \mathrm{~S}$ \\
Face 3 & $a 33$ & $-3 \mathrm{~S}$ & $-2 \mathrm{~S}$ & $-30 \pm 10$ \\
& $a u$ & $-4 \mathrm{~S}$ & -70 & $-\mathrm{S} 7.5 \pm 20$ \\
\multirow{2}{*}{ Face 4} & $a 33$ & $1 \mathrm{~S}$ & $-7 \mathrm{~S}$ & $-30 \pm 6 \mathrm{~S}$ \\
& $a n$ & 0 & $-8 \mathrm{~S}$ & $-42.5 \pm 60$ \\
Face S & $a 33$ & $-1 \mathrm{~S}$ & $-8 \mathrm{~S}$ & $-\mathrm{SO} \pm \mathrm{SO}$ \\
& $a u$ & -40 & -60 & $-\mathrm{SO} \pm 1 \mathrm{~S}$ \\
Face 6 & $a u$ & $-7 \mathrm{~S}$ & -90 & $-82.5 \pm 10$ \\
& $a n$ & $-11 \mathrm{~S}$ & $-\mathrm{SS}$ & $-8 \mathrm{~S} \pm 40$ \\
\hline
\end{tabular}

explanation holds for the lateral faces. Indeed, as presented in Section 2.2, after the powder deposition, the external wall was first melted by the laser followed by the layer core. This means that the core of the sample cools down after the external specimen surface. This explains the development of negative residual stresses on lateral faces in directions 3 and 1 or 2 , as a fonction of the face considered $(2,3,4$ or 5$)$.

The presence of negative values of stress on faces 2 to 6 of the SLM-made samples indicates that this process is well adapted to the fabrication of implants subjected to cyclic loads as residual compression stresses delay crack initiation . However since positive stresses are obtained on the last face of the cube, attention must be paid to the melting path chosen for bone substitute manufacture. A local heat treatment can be used to reduce this stress, for instance by heating the last melted layer, without any material deposit, by the laser beam used (Shiomi et al., 2004).

It must nevertheless be emphasized that all the values appearing in Table 2 are relatively small (o-max $=180 \mathrm{MPa}$, (Emin $=-115 \mathrm{MPa})$ compared to the material conventional yield stress ("'520 MPa).

As no work has been found in the literature concerning residual stress induced by SLM on CP grade 2 titanium, the results obtained in this paper have been qualitatively compared with those on steel provided by Shiomi et al. (2004) . The generation of residual stresses by SLM has been studied on a metal composed of $69.6 \%$ of standard chrome molybdenum steel, $21.7 \%$ of $\mathrm{Ni}$ and $8.7 \%$ of $\mathrm{CuP}$. The authors observed a tensile residual stress on the top surface of about $400 \mathrm{MPa}$. A significant gradient of residual stress was found near this top surface. Indeed, a value of $80 \mathrm{MPa}$ was measured at a distance of $1 \mathrm{~mm}$ from this surface leading to the mean gradient of $320 \mathrm{MPa} / \mathrm{mm}$. Tura comments can be formulated concerning this comparison. First, in our non destructive tests only external surfaces have been examined Consequently, the stress gradient obtained by Shiomi et al. cannot be discussed. Next, the relatively high values of residual stresses determined (Shiomi et al., 2004) are probably due to the specific SLM parameters used. If one compares this method with the welding process, it is well known (Wohlfart, 1986; Lieurade, 1987) that the level of residual stresses, but also their sign, strongly depend on the welding parameters and especially on the energy flux transferred to the sample.
Table 3 - Theoretical and real dimensions of the pattern proposed

\begin{tabular}{lllll} 
& & $\begin{array}{c}\text { Theoretical } \\
(\mu \mathrm{m})\end{array}$ & $\begin{array}{c}\text { Average ex }- \\
\text { perimental } \\
(\mu \mathrm{m})\end{array}$ & $\begin{array}{c}\text { Relative } \\
\text { error } \\
(\%)\end{array}$ \\
\hline \multirow{2}{*}{ Extemal } & PX & 2100 & 2093 & -0.33 \\
dimensions & py & 2870 & 2794 & $-2.6 \mathrm{~S}$ \\
& $\mathrm{PZ}$ & 4980 & 4961 & -0.38 \\
& $\mathrm{~A}$ & 860 & 883 & +2.67 \\
Bearn & $\mathrm{B}$ & 800 & 821 & +2.63 \\
dimensions & $\mathrm{C}$ & $\mathrm{S} 30$ & $\mathrm{~S} 61$ & $+\mathrm{S} .8 \mathrm{~S}$ \\
& $\mathrm{D}$ & 600 & 631 & $+\mathrm{S} .17$ \\
& $\mathrm{E}$ & 800 & 821 & +2.63 \\
& $\mathrm{~F}$ & 600 & 621 & +3.50
\end{tabular}

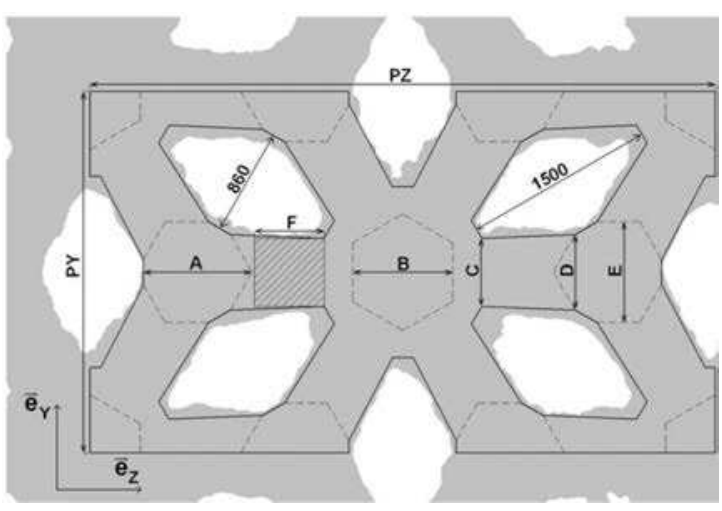

Fig. 6 - Front view of the elementary pattern superimposed on its $C T$ scan image. Cross sections of $X$ oriented beams are plotted using dashed lines.

\subsection{Elementary pattern design}

The leading idea in designing the elementary pattern was to use interconnected 30 irregular "asterisks" made of straight beams connected together. In order to obtain anisotropy of its elastic properties similar to that of human cortical bone, the length and orientation as well as the cross sectional area of these beams were adapted to respect all the criteria cited above. Let $(0 ;$ ex, ey, ez) be the coordinate system attached to this pattern coinciding with its planes of orthotropic symmetry. It was decided to generate the highest stiffness in the $\mathrm{X}$ direction. To reach this aim, four of the straight beams were arranged parallel to this axis. To get lower properties in the $\mathrm{Y}$ and $\mathrm{Z}$ directions, the remaining beams form a six branch asterisk, see Fig. 6. Several configurations were tested leading to the final pattern geometry illustrated by the same Figure. The main theoretical dimensions of this pattern are referenced in this Figure and their values are summarized in Table 4 . They induce the theoretical pattern porosity of $53 \%$. The pore length in $\mathrm{X}$ direction is $900 \mu \mathrm{m}$ and its cross-section in $Y-Z$ plane can be characterized by two diagonals of 860 and $1500 \mu \mathrm{m}$ also indicated in this Figure.

Fig. 2 shows the von Mises stress field for the final pattern geometry, obtained in tension along the $\mathrm{X}$ axis. The applied global tensile stress is $50 \mathrm{MPa}$. The maximal value of this stress is concentrated at the base of the X-oriented beams and reaches $365 \mathrm{MPa}$. This value is lower than the SLM CP Ti conventional yield point and leads to a safety factor $k=1.45$. 
The elastic moduli of the final pattern obtained by the numerical simulations are summarized in Table 4 and compared to those of human cortical bone reported in the literature. It appears from this Table that the bone orthotropy is well respected by the pattern. However, the theoretical longitudinal and transverse moduli are significantly higher than those of bone. For instance, the maximal ratio between the Young 's moduli of the pattern and mandibular bone reaches 1.56 in $\mathrm{Z}$ direction. This observation suggests that the beam cross-sections are too large. Nevertheless, one should remember that the size of beam cross-section results from the strength criterion and safety factor adopted. Consequently, any decrease of beam cross-section area will result in the increase of stresses and violation of this criterion as suggested by the results of Fig. 2. Even so, these moduli are much smaller than the elastic properties of the classical metallic materials used in surgical implants. Indeed, the bulk CP grade 2 titanium typically used in craniomaxillofacial implants leads to a ratio of longitudinal moduli approaching 10.00. These results underline also the remarkable properties of bone tissue compared to the metals such as titanium, wellknown for its high strength-to-weight ratio.

3.4. Measurements of actual dimensions of the pattern and estimate of the geometric tolerance of the samples obtained by SLM

Before carrying out the tensile tests allowing the determination of the elastoplastic properties of the porous structure, it was necessary to estimate the actual size of each specimen and to check the performance of the machine used to precisely reproduce their complex geometry. Measurements of the true dimensions of the gauge part of porous tensile specimens have been carried out using a Phoenix Micro CT scan. The voxel size of the 30 abjects obtained was $10 \mu \mathrm{m}$.

First of all it must be noticed that the melting process en sures good interconnectivity throughout the whole specimen volume; no flaws were detected in all samples within the precision of the Micro CT scan employed. The comparison of the theoretical and typical real pattern geometries is illustrated in Fig. 6. This Figure well illustrates the fact that the real struts dimensions are slightly greater than the theoretical ones.

For each sample, its external dimensions (PX, PY, PZ) were

characterized as well as the cross-sectional sizes of struts defined by dimensions $\mathrm{A}, \mathrm{B}, \mathrm{C}, \mathrm{D}, \mathrm{E}$, and F indicated in the same Figure. Table 3 summarizes all values of the theoretical and average real pattern dimensions .

Analysis of Table 3 indicates that an insignificant difference between the theoretical and real external pattern dimensions exists. The actual enveloping parallelepiped is smaller than the theoretical one. The biggest discrepancy is observed in $\mathrm{Y}$ direction and reaches $-2.65 \%$. However the cross section areas of the actual beams are significantly different from the theoretical ones. The largest mismatch concerns the struts' widths $\mathrm{C}$ and $\mathrm{D}$ where errors exceed $5 \%$. The average ratio between the actual and theoretical cross sections was estimated to be 1.09 leading to an error of about $9 \%$. Consequently, the actual specimen porosity was estimated (by volume measurement) to be $48 \%$ instead of the theoretical value of $53 \%$.

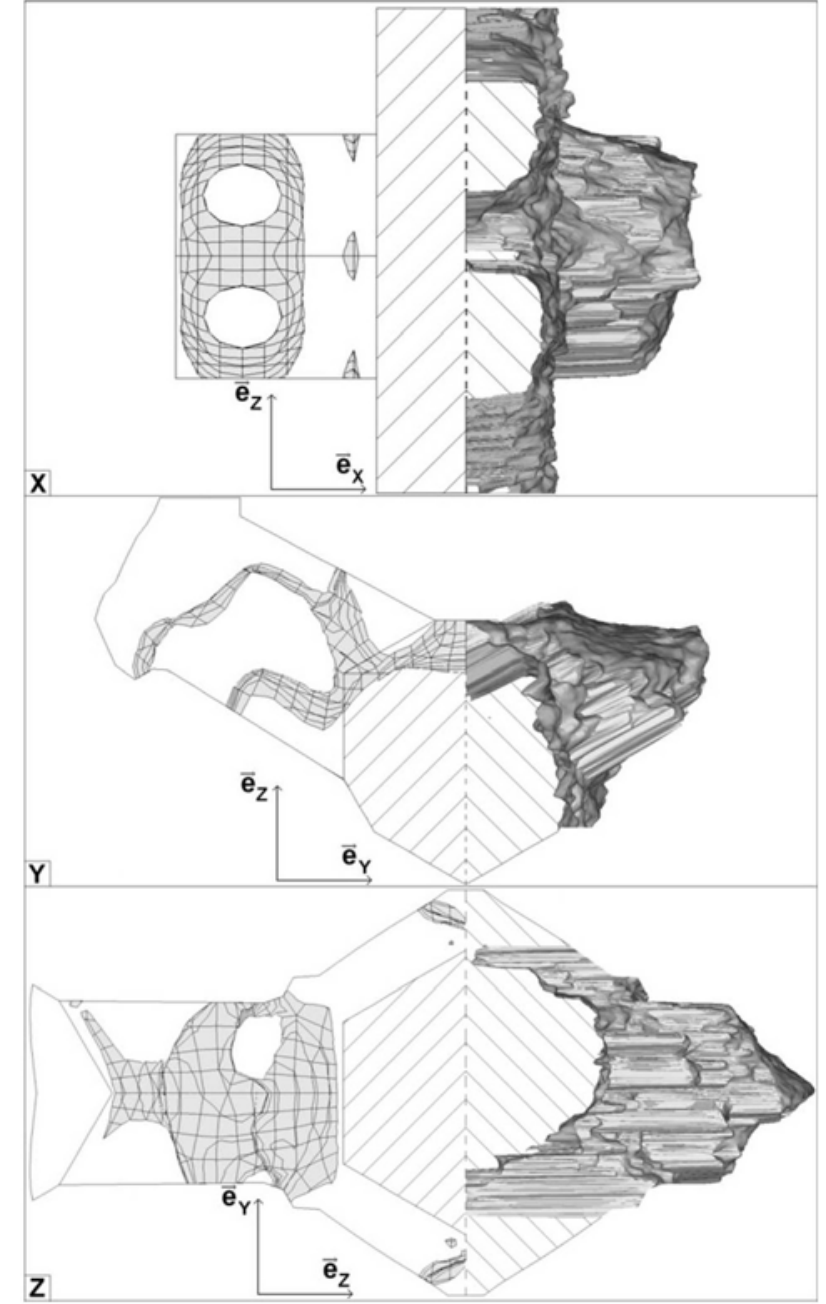

Fig. 7 - Comparison between the iso-surfaces of etM $=0.11$ from FE analyses (on the left) and the experimental fracture facies observed with an InfmiteFocus microscope (on the right) for the three tensile specimens $X$, $\mathrm{Y}$ and $\mathrm{Z}$ respectively.

Moreover, one can observe an important ten-point mean roughness of physical specimens with an $R_{2}$ value of around $45 \mu \mathrm{m}$ estimated using Alicona InfiniteFocus optical device. The arithmetic roughness was evaluated to a value of $R a=8.6 \mu \mathrm{m}$, see also Fig. 7 .

\subsection{Elastoplastic properties of the porous tensile samples. Failure assessment proposition}

In vivo, bones are mostly loaded in compression and bending . Consequently bone substitutes should be tested under such loadings. However in the case of porous substitutes, this stress state induces locally tension, compression, bending or shearing stresses. Even if tension is one of the most critical loadings leading to the structure fracture, it also seems to be necessary to address the problem of the local buckling of struts during compression loading. In the Euler buckling theory the strut slanderness is defined by the ratio between the effective buckling length Le and the square root of the 


\begin{tabular}{|c|c|c|c|c|}
\hline Elastic constants & Units & Pattern & Mandible (Casta:ii.o et al., 2002) & Long bones (Ashman et al., 1984) \\
\hline Ex & & 28,615 & 22,900 & 20,000 \\
\hline Ey & (MPa) & 16,399 & 14,200 & 13,400 \\
\hline Ez & & 16,402 & 10,500 & 12,000 \\
\hline$v x y$ & & 0.15 & 0.19 & 0.35 \\
\hline$v y z$ & & 0.48 & 0.31 & 0.42 \\
\hline$V x z$ & & 0.15 & 0.29 & 0.37 \\
\hline Gxy & & 14,087 & 6000 & 6200 \\
\hline Gyz & $(\mathrm{MPa})$ & 8042 & 3700 & 4500 \\
\hline Gxz & & 8339 & 4800 & 5600 \\
\hline
\end{tabular}

Table 5-Comparison of elastoplastic properties of porous from (Cowin, 1989). Standard Deviation is indicated in brac

tanium samples and bone. Data concerning bones are taken ets.

\begin{tabular}{|c|c|c|c|c|c|c|c|}
\hline & \multicolumn{3}{|c|}{ SLM CPPTi } & \multicolumn{4}{|c|}{ Cortical bone (Cowin, 1989) } \\
\hline & \multirow[b]{2}{*}{ X (Long.) } & \multirow[b]{2}{*}{$Y$ (Trans.) } & \multirow[b]{2}{*}{ Z (Trans.) } & \multicolumn{2}{|c|}{ Tension } & \multicolumn{2}{|c|}{ Compression } \\
\hline & & & & Long. & Trans. & Long. & Trans. \\
\hline E (MPa) & $37,887(1388)$ & $17,987\{1227)$ & $15,824\{566)$ & 17,400 & 9600 & 17,400 & 9600 \\
\hline $\mathrm{Rp}_{0-2}(\mathrm{MPa})$ & $133.3(1.9)$ & $96.2(5.3)$ & $110 . \mathrm{S}\{4.1)$ & 115 & & 182 & 121 \\
\hline $\mathrm{Rm}(\mathrm{MPa})$ & $143.6\{3.6)$ & $129.8(2.5)$ & $141 . i^{\prime}\{4.1)$ & 133 & 51 & 195 & 133 \\
\hline $\mathrm{A} \%$ & $3.0(0.5)$ & $7.8\{1.4)$ & $7.7\{2.7)$ & 2.93 & 3.24 & 2.20 & 4.62 \\
\hline
\end{tabular}

I/A quotient, where $I$ is the moment of inertia and A the area of the strut cross-section. In our pattern the buckling phenomenon is the most likely to occur for the Z-oriented struts of dimensions $0.6 \times 0.6 \times 0.75 \mathrm{~mm}^{3}$. These struts can be considered as short columns with fixed-fixed boundary condition. In this case the slenderness ratio is equal to 2.15. It is commonly accepted that compression members having slenderness ratio smaller than 30 exhibit essentially no instability and fail by yielding or crushing. So, for the value of slanderness ratio of 2.15 there is no risk of buckling. Consequently it seems adequate to test the implants in tension .

Tensile tests on porous specimens were carried out in the three principal directions $\mathrm{X}, Y$ and $\mathrm{Z}$. Since the transversal displacements have not been measured and the hypothesis of volume conservation is not valid for porous materials, it was impossible to calculate the Cauchy's true stress. Consequently, the nominal stress and the true strain of the gauge part of the specimen were calculated, taking into account the real sample dimensions and the correction procedure presented in Appendix.

The apparent Young's moduli, conventional yield stress $\mathrm{Rp}_{0} 2$, ultimate strength $\mathrm{Rm}$ and the corresponding elongation $\mathrm{A} \%$ of the structures were identified in each direction. The results (average values from three tests) are reported in Table 5 and compared with the corresponding properties of the cortical tissue of long bones determined by Cowin (1989). The experimental data are provided for longitudinal and transverse directions in tension and compression.

On the one hand, it was observed in Table 4 of Section 2.4 that the Young's moduli provided by the numerical calculations on the elementary pattern were significantly higher than those of bone. The same remark can be made concerning the experimental results, according to Table 5 . On the other hand, the direct comparison of Tables 4 and 5 shows that these experimental values in $\mathrm{X}$ and $Y$ directions are greater than the theoretical ones. Differences of $32 \%$ and $10 \%$ are calculated respectively taking into account the mean experimental data.

This difference can be partially attributed to the porosity of the actual samples which is lower than theoretically determined. The highest discrepancy observed in $\mathrm{X}$ direction can also be explained by the ratio $\mathrm{L} / 1$ which is relatively high compared to the other specimens. Consequently, the strain measurement is strongly influenced in that case by the bulk parts and the apparent Young's modulus deduced is overestimated .

It can also be observed in Table 5 that the conventional yield point of the porous specimens is a fonction of the sample type. The lowest value of $96.2 \mathrm{MPa}$ is obtained in $Y$ direction and is even greater than the transverse strength of cortical bone of $51 \mathrm{MPa}$ (Cowin, 1989). The highest value of 133.3 $\mathrm{MPa}$ is observed in $\mathrm{X}$ direction and is comparable with the tensile longitudinal strength of $133 \mathrm{MPa}$ reported by the same author. Similar values were provided by other authors, see for instance Reilly and Burstein (1975) and Reilly et al. (1974).

The values of ultimate strength are also higher for the porous structure than for bone. The ultimate apparent elongation of porous samples is relatively weak but remains greater than that of bone for directions $Y$ and $\mathrm{Z}$. In $\mathrm{X}$ direction the low value of titanium samples elongation $\mathrm{A} \%$ of 3.0 is partially due to the important roughness $(\mathrm{Rz}=45 \mu \mathrm{m})$ of the specimens obtained by SLM compared to the crosssection size of struts $\left(500 \times 600 \mu \mathrm{m}^{2}\right)$. Each strut can thus be considered as a notched beam with stress concentrations decreasing the apparent ultimate elongation .

The elasto-plastic properties of human bone in compression are higher than those of the porous structure in tension. 


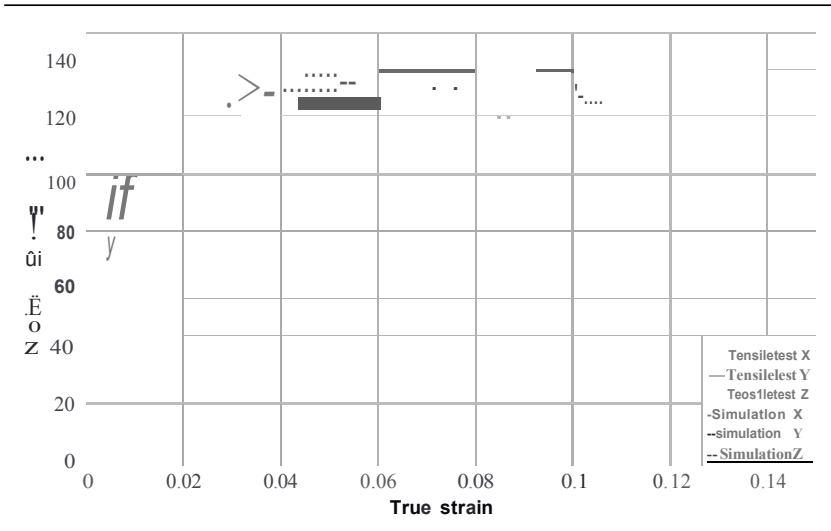

Fig. 8 - Experimental and numerical tensile curves of porous specimens.

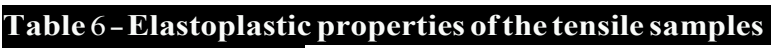
obtained numerically.

\begin{tabular}{lllc} 
& \multicolumn{3}{c}{ Specimen } \\
\cline { 2 - 4 } & \multicolumn{1}{c}{$\mathbf{X}$} & \multicolumn{1}{c}{$\mathrm{y}$} & $\mathbf{Z}$ \\
\hline Young's modulus $(\mathrm{MPa})$ & 29,461 & 17,004 & 17,083 \\
$\operatorname{Rp}_{0.2}(\mathrm{MPa})$ & 125 & 88 & 101 \\
$\operatorname{Rm}(\mathrm{MPa})$ & 143 & 136 & 140 \\
$\operatorname{Emax}$ & 3.0 & 12.5 & 9.1 \\
\hline
\end{tabular}

However, to make a reliable comparison, compression tests on porous samples should be carried out.

The average nominal stress-true strain curves for each type of sample are drawn in Fig. 8. The same Figure shows the stress-strain curves deduced from the Finite Element simulations of porous sample tensile tests. The average actual dimensions of specimens reported in Table 3 were taken into account in these FE analyses.

A good agreement between numerical and experimental curves is obtained until the fracture point of the real specimens. Table 6 summarizes the usual elastoplastic characteristics obtained via these simulations. Instead of ultimate elongations determined experimentally, the total overall strain Emax corresponding to maximal nominal stress was identified. The remaining characteristics were defined in the standard manner.

It should be noted that $\mathrm{FE}$ analyses have been performed without introducing a fracture criterion .

Comparing Tables 5 and 6 , a very good agreement between experimental and numerical values was found except for the Young's moduli in $\mathrm{X}$ direction . However the value appearing in Table 6 remains consistent with the one of Table 4. Furthermore, the pattern defined in this work has a wireframe structure . Consequently, the individual struts are mainly under simple stress states such as tension -compression, shearing or bending. Moreover, the tensile tests performed on porous specimens have shown that all samples broke in a ductile manner. The good concurrence between these data enables the identification of a simple failure criterion for the dimensioning of porous bone substitutes. For these reasons a simple scalar failure criterion seemed to be sufficient to predict the fracture of such porous structures. Quantities such as von Mises stress, equivalent plastic strain, major principal stress and plastic strain were considered. After comparative analysis between numerical and experimental results, the von Mises equivalent plastic strain appeared to be the best candidate. Consequently the following criterion was proposed :

\section{otM ${ }^{0}$ fr}

where ofr $=$ ob-i ax corresponds to the equivalent plastic strain at the maximum stress value of bulk $\mathrm{CP}$ titanium produced by SLM. It is admitted that to be broken a whole strut section has to undergo this level of plastic strain. According to the results presented in Section 3.1 the following critical value was chosen:

ofr $=0.11$.

To illustrate the relevance of the criterion proposed, the loading at which the full strut section experiences the critical plastic strain has been identified and compared with the experimental fracture loads, for each numerical tensile test. The corresponding critical points are marked with a dotted square in Fig. 8. It appears from this Figure that the numerical and experimental fracture points are very close. Fig. 7 shows the comparison between the iso-surfaces of $\mathrm{otM}=0.11$ and the experimental fracture facies observed with an InfiniteFocus microscope. Pictures X, Y and Z concern respectively the three numerical and experimental tensile tests on $\mathrm{X}, \mathrm{Y}$ and $\mathrm{Z}$ porous specimens. The left part of each picture provides the FE predictions of equivalent plastic strain and the right part shows the corresponding broken strut. One can conclude that for the three samples tested the shape and location of the fracture facies and the iso-surfaces of $\mathrm{EtM}=0.11$ concord .

This comparison confirms the pertinence of such a simple criterion for the porous titanium wireframe bone substitutes processed by SLM.

\section{Conclusions}

An elementary pattern of a CPPTi structure mimicking the mechanical properties of bone and favouring bone colonization was developed in this study. This pattern is characterized by a porosity of $53 \%$ due to the periodic oblong pores of relatively important dimensions $0.9 \times 0.86 \times 1.5 \mathrm{~mm}^{3}$.

Analyses performed on the bulk SLM processed samples seemed to reveal that this technology is well adapted to the manufacturing of implants. Indeed, the classical elastoplastic properties of CP Ti samples obtained via this method satisfied the international standards. Moreover, no anisotropy induced by the process was detected on the manufactured specimens. The high strength of the material tested and the existence of residual compression stresses suggested that cyclic loading can safely be applied to the SLM-made structures. To complete these observations, further analyses on the residual stresses existing in the porous structure developed in this study and on its fatigue behaviour would have to be carried out.

Mechanical tests performed on porous tensile samples at ambient temperature and under quasi static conditions 
led to the ductile fracture of individual struts. The critical strain and stress levels corresponded to the ultimate values of these quantities obtained via tensile tests carried out on bulk SLM-made specimens. Consequently, a simple scalar failure criterion was proposed, through experimental tests and their finite element simulations, for the design of SLMmade porous bone substitutes .

\section{Acknowledgement}

The authors wish to thank Dr J.-M . Hiver from Institut Jean Lamour, Ecole des Mines de Nancy for his participation in the computed tomography analysis of the porous samples.

\section{Appendix}

Each tensile specimen can be represented by three distinct volumes with their own stiffness connected in series, see Fig. A.1.

According to this scheme, the stretch of the porous part of the specimen can be estimated allowing the determination of its strain.

Let $\mathrm{L}_{0}, \mathrm{~L}, !_{0}$ and lbe the initial and current lengths of gauge and porous part of the specimen, respectively, see Fig. A.1. Consequently, under the hypothesis of small strains of the bulk part of the gauge length, the stiffness to be taken into account in the correction procedure can be written as

$$
\mathrm{K}=\S_{\text {Lo }-\mathrm{Io}}
$$

where E is the Young's modulus of bulk titanium and So the initial cross section area of the specimen.

The equilibrium of the specimen submitted to the tension force $\mathrm{F}$ allows the calculation of the bulk part elongation.

$$
u=\stackrel{\mathrm{F}}{\mathrm{K}}
$$

The current length of the porous part can be calculated with the current distance between the measurement points and the applied tension force

$\mathrm{I}=\mathrm{L}-\mathrm{Lo}+!_{0}-\stackrel{\mathrm{F}}{\mathrm{K}}$.

Consequently the strain of the porous part can be expressed as:

$=-\ln (1 ;)=\ln \begin{gathered}(\mathrm{L}-\mathrm{Lo}+\mathrm{Io}-k) \\ 10\end{gathered}$

Since the transversal displacements have not been measured and the hypothesis of volume conservation is not valid for porous materials, it was impossible to calculate the Cauchy's true stress.

Consequently the nominal stress defined as below,

$a=\mathrm{F} / \mathrm{So}$

has been used to draw the stress-strain curves for each specimen.

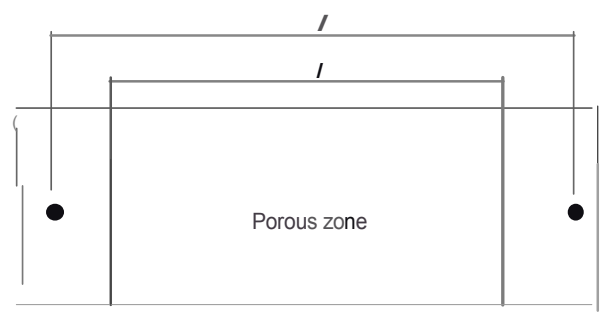

Fig. A.1 - Scheme of the reference points positioning for video-traction.

\section{R E F E R E N C E S}

Ashman, R.B., Cowin, S.C., Van Buskirk, W.C., Rice, J.C., 1984. A continuous wave technique for the measurement of the elastic properties of cortical bone. Journal of Biomechanics 17, 349-361.

Castaii.o, M.C., Zapata, U., Pedroza, A., Jaramillo, J.O., Roldan, S., 2002. Creation of a threedimensional mode! of the mandible and the TMJ in vivo by means of the finite element method . International Journal for Computation and Dent 5, 87-99.

Chen, Y.]., Feng, B., Zhu, Y.P., Wenig, ]., Wang, J.X., Lu, X., 2009. Fabrication of porous titanium implants with biomechanical compatibility. Materials Letters 63, 2659-2661.

Cowin, S.C., 1989. Bane Mechanics, pp. 102, 103, 111-113.

Hein!, P., Müller, L., Kërner, C., Singer, R.F., Müller, F.A., 2008. Cellular Ti-6Al-4V structures with interconnected macro porosity for bone implants fabricated by selective electron beam melting. Acta Biomaterialia 4, 1536-1544.

Hollander, D.A., Von Walter, M ., Wirtz, T., Sellei, R., SchmidtRohlfing, B., Paar, O., Erli, H.J., 2006. Structural, mechanical and in vitro characterization of individually structured Ti-6Al-4V produced by direct laser forming. Biomaterials 27, 955-963.

Karachalios, T., Tsatsaronis, C., Efraimis, G., Papadelis, P., Lyritis, G, Diakoumopoulos, G., 2004. The long-term clinical relevance of calcar atrophy caused by stress shielding in total hip arthroplasty: a 10-year, prospective, randomized study. The Journal of Arthroplasty 19, 469-475.

Krishna , B.V., Bose , S., Bandyopadhyay, A., 2007. Low stiffness porous $\mathrm{Ti}$ structures for load-bearing implants. Acta Biomaterialia 3, 997-1006.

Li, J.P., De Wijn, J.R., Van Blitterswijk, C.A., De Groot, K. , 2006. Porous Ti6Al4V scaffold directly fabricating by rapid prototyping : preparation and in vitro experiment. Biomaterials $27,1223-1235$.

Lieurade, H .P., 1987. Effet de contraintes résiduelles et du rapport $\mathrm{R}$ sur la résistance à la fatigue des éléments soudés. In: Conférence, CETIM, Senlis, p. 99.

ISO 5832-2, 1999. Implants for surgery. Metallic materials . Part 2: unalloyed titanium .

Niu, W., Bai, C., Qiu, G., Wang, Q., 2009. Processing and properties of porous titanium using space holder technique. Materials Science and Engineering: A 506, 148-151.

Oh, 1.-H., Nomura, N., Masahashi, N ., Hanada, S., 2003. Mechanical properties of porous titanium compacts prepared by powder sintering. Scripta Materialia 49, 1197-1202.

Otsuki, B., Takemoto, M., Fujibayashi, S., Neo, M ., Kokubo, T., Nakamura, T., 2006. Pore throat size and connectivity determine bone and tissue ingrowth into porous implants: threedimensional micro-CT based structural analyses of porous bioactive titanium implants. Biomaterials 27, 5892-5900. 
Parthasarathy, J., Starly, B., Raman, S., Christensen, A., 2010. Mechanical evaluation of porous titanium (Ti6Al4V) structures with electron beam melting (EBM). Journal of the Mechanical Behavior of Biomedical Materials 3, 249-259.

Reilly, D.T., Burstein , A.H., 1975. The elastic and ultimate properties of compact bone tissue. Journal of Biomechanics 8, 393-396

Reilly, D.T., Burstein, A.H ., Frankel, V.H., 1974. The elastic modulus for bone. Journal of Biomechanics 7, 35-42.

Shiomi, M ., Osakada, K ., Nakamura, K ., Yamashita, T., Abe, F. 2004. Residual stress within metallic mode! made by selective laser melting process. CIRP Annals-Manufacturing Technology 53, 195-198
Vandenbroucke, B., Kruth, J.-P., 2007 . Selective Laser melting of biocompatible metals for rapid manufacturing of medical parts. Rapid Prototyping Journal 13, 196-203.

Wohlfart, H., 1986. Residual stress as a consequence of welding. In: Advance in Surface Treatments, vol. 4. Pergamon.

Xue, W., Krishna, B.V., Bandyopadhyay, A., Bose, S., 2007. Processing and biocompatibility evaluation of laser processed porous titanium. Acta Biomaterialia 3, 1007-1018.

Yook, S.-W., Kim, H .-E., Koh, Y.-H., 2009. Fabrication of porous titanium scaffolds with high compressive strength using camphene-based freeze casting. Materials Letters 63, 1502-1504. 